\title{
Trauma Surgery Octe Care Open Outcome of femoral fractures care as a measure of trauma care between level I and level II trauma systems in Israel
}

\author{
A Khoury, Y Weil, M Liebergall, R Mosheiff, The Israeli Orthopedic Trauma Group
}

Hadassah University Hospital, Jerusalem, Israel

\section{Correspondence to}

Dr Amal Khoury, Orthopedic Trauma and Reconstructive Surgery, Hadassah Hospital \& Hebrew University School of Medicine, Ein-Kerem, Jerusalem 91120, Israel; akhoury@hadassah.org. ile000041

Received 25 August 2016 Accepted 18 September 2016

To cite: Khoury A, Weil $Y$, Liebergall $\mathrm{M}$, et al. Trauma Surg Acute Care Open Published Online First: [please include Day Month Year] doi:10.1136/tsaco2016-000041

\section{ABSTRACT}

Background Our hypothesis in this study was that the outcome of patients with femur fractures would be favorable in a level I trauma center (LITC).

Methods A prospective multicenter cohort study. 5 LITC and 6 regional (level II) trauma centers (RTCs) were enrolled to participate in the study. A total of 238 patients suffering from a femoral fracture were recruited to the study. 125 patients were treated in LITCs and 113 in RTCs. Data were extracted from the emergency medical services ambulances, emergency department records, patient hospitalization and discharge records, operating room records, and the national trauma registry (for LITCS). A study questionnaire was administered to all participating patients at discharge, 6 weeks and 6 months postoperatively. The following parameters were studied: mechanism of injury, time from injury to the hospital, Injury Severity Score, classification of femoral fracture, additional injuries, medical history, time to surgery, implant type, skill level of the surgical team, type of anesthesia, length of stay and intensive care unit (ICU) stay, postoperative and intraoperative complications and mortality.

Results There was a significant difference in the modality of patient transfer between the 2 study groups - with the LITC receiving more patients transported by helicopters or medical intensive care. Time to surgery from admission was shorter in the LITC. Length of stay, ICU stay, and mortality were similar. In the LITCs, 47\% of the procedures were performed by residents without the supervision of an attending surgeon, and in the RTCs $79 \%$ of the procedures were performed with an senior orthopaedic surgeon. Intraoperative and immediate complication rates were similar among the 2 groups.

Conclusions A femoral shaft fracture can be successfully treated in an LITC and RTC in the state of Israel. Both research and policy implementation works are required. Also, a more detailed outcome analysis and triage criteria for emergency are desired.

Level of evidence $I I$.

\section{INTRODUCTION}

Classified and managed trauma care systems were introduced during recent decades in order to facilitate and coordinate the care of severely injured patients, as well as to improve survival and outcome. ${ }^{1}$ Guidelines have been published regarding the organization, resources, and availability of personnel and specialized equipment necessary for the care of the patient with polytrauma. ${ }^{2}$ Large-scale studies have demonstrated that when treating severely injured patients in trauma centers, as compared with non-trauma centers, there is a significant reduction in mortality and cost to society. $^{34}$

As trauma systems evolve outside the USA, several models of trauma care systems have been accepted worldwide, with the Israeli system adopting the American model with some modifications. ${ }^{5}$ Official guidelines were published and certification of trauma systems has gradually taken place. ${ }^{6}$

Femoral shaft fractures are a relatively common injury in the patient with polytrauma ${ }^{7}$ and have been the center of controversy, especially regarding the optimal timing for their treatment, ${ }^{8}$ over the past few years. They have also served as a benchmark for quality control in trauma centers. ${ }^{9}$ Differences exist between trauma centers regarding the timing, type, and surgical staff involved and surgical procedures for the treatment of these highenergy injuries.

To the best of our knowledge, little has been done to evaluate the quality and performance of the classified trauma system in Israel. Our hypothesis, based on internationally published data, was that the outcome of patients with femur fractures would be favorable in level I trauma centers (LITCs) as compared with regional trauma centers (RTCs) as regards mortality and morbidity.

The aim of this study was to prospectively compare level I and RTCs (level II) regarding the epidemiology and treatment of patients with trauma with femoral shaft fractures, as a measure for quality control.

\section{PATIENTS AND METHODS}

Study design

A prospective, multicenter cohort study. Five LITCs and six RTCs (level II) were enrolled to participate in the study. All centers met the criteria specified in the requirements for the certification of trauma centers in Israel, as published by the Ministry of Health at that time. ${ }^{6}$ Funding for the study was granted by the Israel National Institute for Health Policy and Health Services Research.

Inclusion criteria: skeletally mature ( $>18$ years of age) patients suffering from femoral shaft fracture (AO/OTA 32 group) amenable for surgical fixation who were admitted to the recruiting centers were eligible for participation in the study. Excluded were patients older than age 65, patients with pathological fractures, or patients unable to sign an informed consent for participation in the study prior to discharge from the hospital. Also included in the study were mortality cases of patients with trauma with femoral shaft fractures within the recruiting centers. 
Data collection

Data were extracted from the emergency medical services ambulance records; emergency department records; patient hospitalization and discharge records; operating room records and national trauma registry (for LITCs). A structured study questionnaire was administered to all participating patients to be completed at discharge, 6 weeks and 6 months postoperatively. The following parameters were studied: mechanism of injury; arrival time from injury to admission; Injury Severity Score (ISS); classification of femoral fracture (AO/OTA); additional injury; medical history; time to surgery; implant type; skill level of the surgical team; type of anesthesia; length of stay (including intensive care unit (ICU) stay) postoperative and intraoperative complications and mortality.

\section{Statistical analysis}

Power analysis, with an assumption of $10 \%$ difference in complication rate (in favor of the LITC), was used to calculate the required sample size of 185 patients in each group assuming a power of 0.8 and a significance level of 0.05 . Categorical variables were tested using Fisher's exact test and a two-tailed Student's t-test for continuous variables. Multivariate analysis was carried out using logistic regression for categorical dependent variables. SPSS (IBM statistics, Chicago, Illinois, USA) was used as the software package.

\section{RESULTS}

A total of 238 patients were recruited to the study. 125 patients were treated in LITCs and 113 in RTCs. Patient demographics are depicted in table 1 . Blunt trauma accounted for the vast majority of injury mechanisms, with similar rates between the two study groups. The distribution of associated injuries (chest, abdomen, and other skeletal injuries) was similar between the two groups with a tendency for higher head injury rates in the LITCs. The vast majority of patients were healthy with similar rates $(19 \%)$ of associated comorbidities. The severity of associated injuries as measured by ISS was similar between the two study groups.

Table 1 Patient demographics among the study groups

\begin{tabular}{llll}
\hline & Level I & Level II & p Value \\
\hline $\begin{array}{l}\text { Age (average } \pm \text { SD) } \\
\text { Mechanism of injury }\end{array}$ & $33.3 \pm 13.5$ & $33 \pm 12.1$ & NS \\
$\quad$ Motor vehicle accident & $66 \%$ & $64 \%$ & NS \\
Fall from height & $10.3 \%$ & $8 \%$ & NS \\
Penetrating & $6 \%$ & $4 \%$ & NS \\
Other & $11 \%$ & $15 \%$ & NS \\
Unknown/missing & $6.7 \%$ & $9 \%$ & NS \\
Associated injuries & & & \\
Other skeletal & $61.3 \%$ & $59.9 \%$ & NS \\
Abdominal & $14.3 \%$ & $15.9 \%$ & NS \\
Chest & $24.4 \%$ & $29.2 \%$ & NS \\
Head & $19.3 \%$ & $11.5 \%$ & 0.18 \\
ISS & & & \\
9 & 46 & 50.5 & NS \\
$10-14$ & 21.4 & 19.3 & NS \\
$16-24$ & 11.1 & 12.8 & NS \\
$25-75$ & 21.4 & 17.4 & NS \\
Associated comorbidities & $18.5 \%$ & $19 \%$ & \\
\hline NS, not significant. & & & \\
\end{tabular}

Table 2 Fracture data and treatment modalities among the study groups

$\begin{array}{lll}\text { Level I } & \text { Level II } & p \\ (\%) & (\%) & \text { Value }\end{array}$

\begin{tabular}{llll}
\hline Fracture classification (AO/OTA) & & & \\
$32-\mathrm{A}(1-3)$ & 39 & 48 & NS \\
$32-\mathrm{B} / \mathrm{C}$ & 56 & 47 & NS \\
Bilateral femur & 6 & 5 & NS \\
$\quad$ Hip involvement & 12.7 & 7.9 & NS \\
$\quad$ Open fractures & 25 & 37 & NS \\
$\quad$ Open reduction & 24 & 21 & NS \\
$\begin{array}{l}\text { Implant type } \\
\text { Antegrade nail }\end{array}$ & 78 & 73 & NS \\
$\begin{array}{l}\text { Other (plate, retrograde nail, } \\
\text { cephalomedullary nail) }\end{array}$ & 17 & 22 & NS \\
$\quad$ Unknown & 5 & 5 & NS \\
\hline NS, not significant. & 5 & &
\end{tabular}

There was a significant difference in the modality of patient transfer between the two study groups, with the LITCs receiving more patients transported by helicopters or medical intensive care (MIC) ambulances than the RTCs (53\% vs 44\%, p<0.05).

The femoral shaft fracture morphology (according to the AO/ OTA classification) was similar among the two study groups (table 2) with about half of the fractures classified as simple (AO/OTA type 32A) and the rest more comminuted (types 32B and $32 \mathrm{C}$ ). The vast majority of cases were treated by reamed, locked, antegrade intramedullary nails (table 2) and the rest were treated by other devices (cephalomedullary nails, plates, or retrograde nails) without a significant difference between the two trauma center types. Open reduction rate during surgery was similar among the study groups. Time to surgery was shorter in the LITCs where $69 \%$ of patients were operated on within 8 hours of admission as compared with $47 \%$ in the RTCs.

However, in the LITCs, more surgical procedures were performed together with the femoral fracture fixation $157.2 \%$ of patients vs $42.1 \%, \mathrm{p}<0.05)$. Also, fewer additional surgical procedures were performed after the index surgery in the LITCs (31\%) as compared with the RTCs $(46.5 \%, \mathrm{p}<0.05)$.

Length of stay, ICU stay, and mortality were similar among the two study groups (table 3 ).

\begin{tabular}{|c|c|c|c|c|}
\hline & \multicolumn{2}{|c|}{ LITC } & \multicolumn{2}{|c|}{ RTC } \\
\hline & $N$ & Percent & $\mathbf{N}$ & Percent \\
\hline \multicolumn{5}{|l|}{ Discharge } \\
\hline Home & 71 & 56.3 & 64 & 56.1 \\
\hline Rehabilitation & 41 & 32.2 & 34 & 29.8 \\
\hline Other hospital & 4 & 3.2 & 7 & 6.1 \\
\hline Death & 9 & 7.1 & 4 & 3.5 \\
\hline \multicolumn{5}{|l|}{ ICU stay } \\
\hline Yes & 17 & 13.5 & 11 & 9.6 \\
\hline \multicolumn{5}{|l|}{ Length of stay } \\
\hline More than 11 days & 63 & 50.0 & 58 & 51.0 \\
\hline
\end{tabular}


Table 4 ISS, surgical team, and associated injuries

\begin{tabular}{|c|c|c|c|c|}
\hline & \multicolumn{2}{|c|}{ LITC } & \multicolumn{2}{|c|}{ RTC } \\
\hline & $\mathrm{N}$ & Percent & $N$ & Percent \\
\hline \multicolumn{5}{|l|}{ ISS } \\
\hline $9-14$ & 30 & 35.3 & 30 & 39.5 \\
\hline+16 & 33 & 80.3 & 28 & 73.7 \\
\hline \multicolumn{5}{|l|}{ Senior surgeon } \\
\hline Attending & 35 & 54.7 & 45 & 52.9 \\
\hline Non-attending * & 23 & 41.8 & 8 & 36.4 \\
\hline \multicolumn{5}{|l|}{ Associated injuries } \\
\hline Skeletal & 50 & 65.8 & 44 & 63.8 \\
\hline Non-orthopedic** & 71 & 56.8 & 33 & 67.3 \\
\hline
\end{tabular}

As for the training level of the physicians who performed the femoral fracture fixation, there were significant differences among the study groups (table 4). In the LITCs, $47 \%$ of the procedures were performed by residents without an attending surgeon's supervision, while in the RTCs $79 \%$ of the procedures were performed in the presence of an attending orthopedic surgeon. A logistic regression found a significantly higher likelihood of the presence of an attending orthopedic surgeon in LITCs during the daytime (07:00-15:00) versus nighttime (00:00-06:59, OR $6.695 \%$ CI 2.6 to 16.7).

Intraoperative and immediate complication rates were similar among the two study groups (including orthopedic and nonorthopedic complications) with eight cases in the LITCs as compared with four in the RTCs.

\section{DISCUSSION}

This study described the similarities and differences in treating high-energy femur fractures in level I and level II trauma centers in Israel. The main findings were that epidemiology regarding age; mechanism and severity of injury; associated injuries and comorbidities were similar among the two hospital categories. We also found similarities regarding the fracture types: method of fixation and intraoperative complication rates. Differences between the two hospital types were found in transport methods to the hospital; time from admission to surgery; staged versus simultaneous surgery and surgeon skill level. No differences were found regarding complications or reoperation rates between the two centers.

The similarities and differences in trauma centers in this study seem counterintuitive, especially in regard to the severity of trauma dictating evacuation to trauma centers, which was the model used for the establishment of trauma systems in Israel. These results, however, do not reflect the data published by the Israel National Trauma Registry. ${ }^{10}$ According to this recent report, dealing with more than 36000 trauma admissions, the number of patients with an ISS $>16$, patients who were hospitalized in ICUs and overall mortality, were all significantly higher in LITCs. The likely reason for this contradiction is that the study may be underpowered due to a relatively small sample size. Only about $34 \%$ of the patients from both study groups were with an ISS of 16 and above, up to a total of 80 of the 235 patients. Another finding regarding the Israel triage system is that most ICU ambulances and helicopters transport their patients to LITCs; however, this fact did not affect the patient population, as mentioned earlier. A previous study dealing with evacuation of patients from multicasualty events in Israel ${ }^{11}$ had shown some severe triage errors in the emergency evacuation to trauma centers. However, it is noteworthy to mention that some 'level II' trauma centers in Israel are well equipped and staffed, and are short of only one or two criteria to become an LITC, and can therefore offer similar care for many patients akin to that received at an LITC.

A significant difference between the two types of trauma centers is shorter time from injury to surgery and more simultaneous surgical procedures being done in LITCs. This can be explained by the availability of additional operating rooms and more on-call surgical disciplines (eg, neurosurgery, maxillofacial surgery, cardiothoracic surgery) in LITCs, as mandated by regulations. $^{6}$ This fact, however, did not significantly alter the outcome in our group of patients as regards morbidity, mortality, or outcome of femur fracture fixation.

An interesting finding was that unsupervised residents performed about $47 \%$ of procedures in LITCs in contrast to only $21 \%$ in RTCs, again without significant differences in fracture healing or postoperative complications. A significant correlation with unsupervised resident surgery was the time of day (ie, after 15:00 and before 07:00). This topic is not thoroughly dealt with in the literature. In a 1999 study from Edinburgh, ${ }^{12}$ around $50 \%$ of all orthopedic trauma procedures were performed without the attendance of a senior surgeon and in an additional $20 \%$ the senior trauma surgeon was present but not scrubbed. There was no mention of different outcomes between supervised and unsupervised procedures. In an Australian study, where more than 6000 orthopedic trauma procedures were studied, 59\% were unsupervised. ${ }^{13}$ Surprisingly, complications such as hardware failure and malunion were more frequent in the supervised group. In contrast to these studies, two more recent studies do not support these conclusions. In one study comparing a level II teaching trauma center with a non-teaching hospital with similar resources and activities ${ }^{14}$ where residents were present in the trauma center, severe errors in triage, resuscitation, and adverse outcomes were significantly more common. In a recent study dealing with proximal femoral fracture in the elderly, mortality and complications were significantly higher in patients treated without the supervision of a scrubbed senior surgeon. ${ }^{15}$

In our study, despite the high number of associated injuries, $66 \%$ of the patients were with an ISS $<16$, with an average age of 33, and therefore were more resilient than the average polytrauma patient. Another explanation is the fact that femur shaft fractures treated with antegrade, reamed, locked intramedullary nails have extremely high union rates. ${ }^{16}{ }^{17}$ Since about half of the fractures were of the more simple type, the results may be more 'forgiving' for less trained surgeons.

There are some limitations in our study. First, despite the design, it seems to be underpowered given the low observed complication rate observed in actual fracture surgery. The fact that there were no observed differences in patient profiles aforementioned strengthens this point. A more meticulous analysis of the results, such as measuring malunions in terms of length and rotation, or evaluation of intraoperative blood loss, may have yielded different results. Also, a more detailed analysis of reduction quality and outcome regarding extension of the fracture into the joints (hip, knee), as has happened in many cases, might have influenced the study. The fact that since the time of this study several dedicated orthopedic trauma surgeons were introduced to some level I centers may change the results if this study were to be repeated today.

In conclusion, femoral shaft fracture can be successfully treated both in LITCs and in RTCs in the State of Israel. Some 
further additional work, both in research and policy implementation, is required in order to define the minimal training level of surgeons performing these procedures. A more refined outcome analysis and triage criteria for emergency services treating patients with trauma with femoral shaft fractures are needed.

Acknowledgements The authors acknowledge Sharon Eylon, MD, for assistance in data collections, and Malka Avitzour for statistical processing.

Collaborators The Israeli Orthopedic Trauma Group: M Liebergall, R Mosheiff, A Khoury, Y Weil, Hadassah Ein Kerem, ${ }^{*}$ Y Bar-Ziv, Asaf Harofeh Medical Center, B Kish, Meir Hospital, A Korngreen, Soroka Medical Center, N Ron, Hillel-Yaffemedical Center, N Rozen, Rambam Healthcare Campus, S Sagiv, Kaplan Medical Center, N Shazar, Sheba Tel Hashomer Medical Center, Tantzman M. Ha'Emek Medical Center, $S$ Velkes, Rabin Medical Center, G Volpin, Galil Ma'aravi Medical Center of Nahariya.

Contributors YW has equally contributed to the writing of the manuscript as AK.

Funding The Israel National Institute for Health Policy and Health Services Research. Grant number 712002/ $\chi$.

Competing interests None declared.

Patient consent Obtained.

Ethics approval The study was approved by the local ethics committee in each of the participating centers.

Provenance and peer review Not commissioned; externally peer reviewed.

Open Access This is an Open Access article distributed in accordance with the Creative Commons Attribution Non Commercial (CC BY-NC 4.0) license, which permits others to distribute, remix, adapt, build upon this work non-commercially, and license their derivative works on different terms, provided the original work is properly cited and the use is non-commercial. See: http://creativecommons.org/ licenses/by-nc/4.0/

\section{REFERENCES}

1 Trauma care systems quality improvement guidelines. American College of Emergency Physician. Ann Emerg Med 1992;21:736-9.

2 Resources for optimal care of the injured patient: an update. Task Force of the Committee on Trauma, American College of Surgeons. Bull Am Coll Surg 1990;75:20-9.
3 MacKenzie EJ, Rivara FP, Jurkovich GJ, Nathens AB, Frey KP, Egleston BL, Salkever DS, Scharfstein DO. A national evaluation of the effect of trauma-center care on mortality. N Engl J Med 2006;354:366-78.

4 MacKenzie EJ, Weir S, Rivara FP, Jurkovich GJ, Nathens AB, Wang W, Scharfstein DO, Salkever DS. The value of trauma center care. J Trauma 2010;69:1-10.

5 Ben Abraham R, Heruti RJ, Abramovitch Y, Marganit B, Shemer J, Stein M. Structure and process components of trauma care services in Israeli acute-care hospitals. Injury 1998:29:43-6.

6 Berelovitz Y. Measures for recognition in a Trauma Center Jerusalem 2004 [12-22014]. http://www.health.gov.il/hozer/mr33_2004.pdf (accessed Aug 2016).

7 Hildebrand F, Giannoudis P, Kretteck C, Pape HC. Damage control: extremities. Injury 2004;35:678-89.

8 Nahm NJ, Vallier HA. Timing of definitive treatment of femoral shaft fractures in patients with multiple injuries: a systematic review of randomized and nonrandomized trials. J Trauma Acute Care Surg 2012;73:1046-63.

9 Smith JS Jr, Martin LF, Young WW, Macioce DP. Do trauma centers improve outcome over non-trauma centers: the evaluation of regional trauma care using discharge abstract data and patient management categories. J Trauma 1990;30:1533-8.

10 Peleg K, Moskovich-Barkai J, Givon A, Goldman S. A Decade of Trauma Injuries in Israel 2000-2009-National Report 2011. Tel Aviv, Israel: Israel National Center fo Trauma \& Emergency Medicine Research, The Gertner Institute for Epidemiology \& Health Policy, Sheba Medical Center, Tel Hashomer, 2011. Contract No.: ISBN 978-965-91092-1-0

11 Einav S, Feigenberg Z, Weissman C, Zaichik D, Caspi G, Kotler D, Freund HR. Evacuation priorities in mass casualty terror-related events: implications for contingency planning. Ann surg 2004;239:304-10.

12 Sutherland AG, Brooksbank A, Parwez T, Finlayson DF. Who actually does orthopaedic operating? I R Coll Surg Edinb 1999;44:91-3.

13 Harris IA, Lin C. Orthopaedic trauma surgery performed by unsupervised and supervised trainees: complication rates compared. J Orthop Surg (Hong Kong) 2007:15:264-6.

14 Bukur M, Singer MB, Chung R, Ley EJ, Malinoski DJ, Margulies DR, Salim A. Influence of resident involvement on trauma care outcomes. Arch Surg 2012:147:856-62.

15 Khunda A, Jafari M, Alazzawi S, Mountain A, Hui AC. Mortality and re-operation rate after proximal femoral fracture surgery by trainees. I Orthop Surg (Hong Kong) 2013;21:87-91

16 Ricci WM, Gallagher B, Haidukewych GJ. Intramedullary nailing of femoral shaft fractures: current concepts. J Am Acad Orthop Surg 2009;17:296-305.

17 Winquist RA, Hansen ST Jr, Clawson DK. Closed intramedullary nailing of femoral fractures. A report of five hundred and twenty cases. J Bone Joint Surg Am 1984;66:529-39 